\title{
Computational Fluid Dynamic Optimization of Supply and Return Duct Position for Zone Air Distribution
}

\author{
Bashir E. Kareem*, Younis K. Khdir \\ Department of Technical Mechanical and Energy Engineering, Erbil Technical Engineering College, Erbil Polytechnic University, Erbil, \\ Kurdistan Region, Iraq
}

\begin{abstract}
${ }^{*}$ Corresponding author:
Bashir E. Kareem,

Department of Technical

Mechanical and Energy

Engineering, Erbil Technical

Engineering College, Erbil

Polytechnic University, Erbil,

Kurdistan Region, Iraq.

E-mail: bashir.kareem@epu.

edu.iq
\end{abstract}

Received: 15 July 2021

Accepted: 23 November 2021

Published: 30 December 2021

\section{DOI}

10.25156/ptj.v11n2y2021.pp69-78

\section{A B S T R A C T}

Air conditioning accounts for roughly half of all energy consumption in residential buildings. Today's issue is optimizing the air conditioning system and methods of conveying heated and cooled air to prevent additional energy consumption. The optimal supply and return duct position is studied and the results based on the minimum air temperature and pressure in the room, while the room air distribution is taken into account. The main objective of air conditioning, which is impacted by duct position, is to provide thermal comfort in the room. Using Computational Fluid Dynamic, a controlled zone is designed and analyzed in the room with fourteen different duct position cases (ANSYS - FLUENT). The duct position is then optimized based on thermal comfort and uniform distribution of air temperature. The findings revealed that the location of supply and return ducts has a significant impact on minimum room air temperature and room air distributions. Across all cases, the temperature ranges from (294 K to $297 \mathrm{~K})$.

Keywords: Air distributions; Computational fluid dynamic; Duct position; Thermal comfort

\section{INTRODUCTION}

Computational fluid dynamic (CFD) is a powerful optimization tool used for numerical analysis and investigation. Air conditioning is dealing with controlling indoor conditions, which is crucial presently ( $\mathrm{Li}$ and Nielsen, 2011). Due to a lack of electricity and a high demand for cooling and heating loads in Iraq, reducing power consumption for air conditioning is mandatory (Kareem, 2018). People spend more than $90 \%$ of their time indoors; various parameters that affect human comfort must be considered when designing an air conditioning system; these parameters include both dry and wet bulb temperatures, heat production, relative humidity, indoor air quality, and quantity with air distribution (Kareem, 2018). Many researchers have investigated air distribution using CFD analysis; their work and findings will be summarized.

(Bamodu et al., 2017) used CFD to numerically examine a 4-way cassette forced air system in cooling mode and compared it to two rooms with different design arrangements. (Ding et al., 2017) investigated how increasing both supply outlet and return air inlets leads to an increase in the area of unidirectional flow regions of the main flow region to avoid indoor vortex and turbidity.
(Du et al., 2016) used CFD to analyze the thermal indoor conditions for the steam turbine room in a power plant and discovered that numerical and experimental results agreed well. (Sudhangshu Sarma, 2016) used CFD to investigate the wind stream and temperature field inside a room with different air system positions. (Pillai et al., 2016) conducted a review of numerical and experimental studies on temperature distribution and airflow in air conditioning systems. A numerical study was conducted to predict the indoor air distribution with impinging mixing ventilation (MV) and impinging jet ventilation (IJV) systems in heating mode, and the results revealed that the average age for breathing the air of IJV is $37-47 \%$ less than that of MV with a different pattern of airflow (Ye et al., 2019). A study used multi-objective optimization to optimize the performance of underfloor air distribution in a classroom in terms of indoor air quality, energy savings, and thermal comfort criteria; the results had optimal conclusions as; underfloor diffuser beside seats, return diffuser at $1.5 \mathrm{~m}$ height from floor, supply air temperature around $18^{\circ} \mathrm{C}$, air change per hour around $14 \mathrm{ACH}$ (Shokrollahi et al., 2020). CFD analysis was used to evaluate the performance of air distribution in Earth Air Tunnel Heat Exchanger, and the best condition is when both the supply and return diffusers are on the same side of the room (Khatri et al., 2017). CFD - fluent was used to simulate a new type of diffuser 
to improve air distribution, and the results revealed that the optimum design of fin angle will be between $\left(45^{\circ}\right.$ and

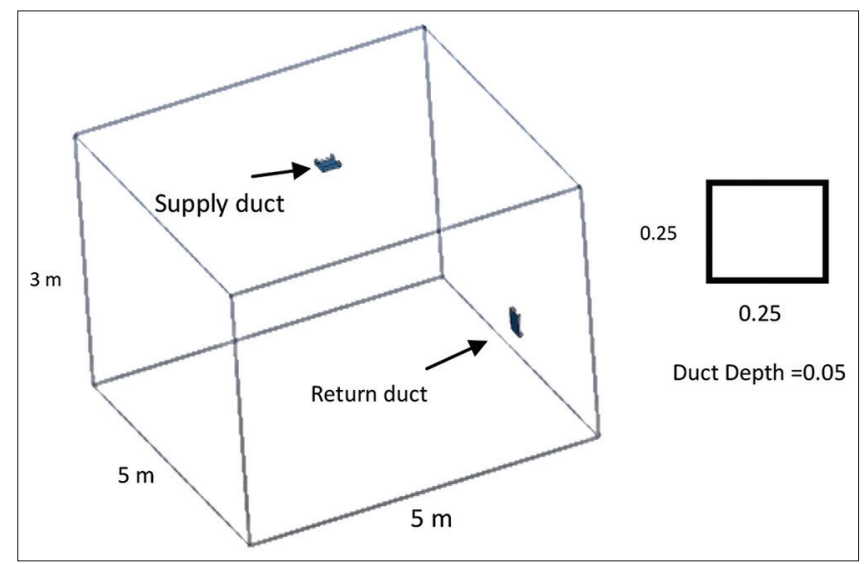

Figure 1: Shows the dimensions of the room and the ducts

Table 1: Demonstrates various scenarios for the positioning of supply and return air ducts

\begin{tabular}{|c|c|}
\hline $\begin{array}{l}\text { Case } \\
\text { no. }\end{array}$ & Position of supply and return ducts \\
\hline 1 & Supply duct at top and return duct at bottom @ the same side \\
\hline 2 & Supply duct at the bottom and return duct at top @ same side \\
\hline 3 & $\begin{array}{l}\text { Supply duct and return duct from ceiling @ } 1 \text { supply and } 1 \\
\text { return }\end{array}$ \\
\hline 4 & $\begin{array}{l}\text { Supply duct and return duct from ceiling @ } 2 \text { supply and } 2 \\
\text { return }\end{array}$ \\
\hline 5 & Supply duct at top and return duct at bottom @ opposite side \\
\hline 6 & $\begin{array}{l}\text { Supply duct at the bottom and return duct at top @ } \\
\text { opposite side }\end{array}$ \\
\hline 7 & Supply duct and return duct from top @ same side \\
\hline 8 & Supply duct and return duct from bottom @ same side \\
\hline 9 & Supply duct and return duct from top @ different side \\
\hline 10 & Supply duct and return duct from bottom @ different side \\
\hline 11 & Supply duct at the ceiling and return duct at the top \\
\hline 12 & Supply duct at top and return duct at the ceiling \\
\hline 13 & Supply duct at the ceiling and return duct at the bottom \\
\hline 14 & Supply duct at the bottom and return duct at the ceiling \\
\hline
\end{tabular}

$50^{\circ}$ ) (Ni et al., 2017). CFD has simulated a new design of a classroom ventilation system that can minimize COVID-19 pandemic diffusion. Thermal comfort criteria, as well as energy savings, have been evaluated, and a comparison of slot diffusers, ceiling squared diffusers, and traditional diffusers have been performed (Ascione, 2021). In the IJV system, the location of the ceiling exhaust has been investigated. CFD is being used to optimize the mean age of air and thermal comfort. The results showed that locating the ceiling exhaust in the center has a longer age of air and locating the ceiling exhaust near a thermal source will improve heat removal efficiency (Qin and Lu, 2021).

(Thakur Dipendrasingh and Parth, 2014) used four different settings to examine a laboratory room (fan, Air conditioning, fan, and air conditioning, and effect of air system position). The impact of area, various cooling supplies, ventilation, and returns on temperature distribution has been investigated (Abou-Deif and Khalil, 2013). The investigation of various parameters on the temperature distribution and the flow field was revealed (Hassan et al., 2013). (Lee et al., 2013) (Lee et al., 2013) investigated the overall heat transfer coefficient of the human body in a variety of cooling situations, including radiant floor heating and convective air heating. (Pillai et al., 2016) (Pillai et al., 2016) investigated the effect of split unit location on room temperature and pressure. (Ni et al., 2017) (Ni et al., 2017) used CFD to optimize energy savings for small data centers by simulating airflow and thermal distribution while taking the airflow outlet angle and tile into account. (Song and Meng, 2015) utilized double rows of windows to increase thermal comfort. To optimize the ventilation performance in a classroom, fluent CFD was done on four unique ventilation systems. (Ye et al., 2020) numerically simulated the thermal comfort and temperature gradient in an IJV, and their findings revealed that an optimal height (1.2-1.5 $\mathrm{m}$ above the floor) is recommended for the best overall performance of the

Table 2: Shows how the position of the supply and return air ducts varies with average room temperature and pressure for the entire volume and lower half of the room

\begin{tabular}{|c|c|c|c|c|}
\hline Case no. & Position of supply and return ducts & $\begin{array}{c}\text { Room } \\
\text { temperature }\end{array}$ & $\begin{array}{l}\text { Lower half of } \\
\text { room temperature }\end{array}$ & $\begin{array}{c}\text { Room } \\
\text { pressure Pa. }\end{array}$ \\
\hline 1 & Supply duct at top and return duct at the bottom at the same side & 295.059 & 294.875 & 28.0601 \\
\hline 2 & Supply duct at the bottom and return duct at the top at the same side & 295.071 & 295.247 & 28.0853 \\
\hline 3 & 1 Supply duct and 1 return duct at ceiling & 294.801 & 294.56 & 27.4586 \\
\hline 4 & 2 Supply ducts and 2 return ducts at ceiling & 294.521 & 293.885 & 7.10985 \\
\hline 5 & Supply duct at top and return duct at the bottom from the opposite side & 295.629 & 295.448 & 28.6077 \\
\hline 6 & Supply duct at the bottom and return duct at the top from the opposite side & 295.553 & 295.697 & 28.3249 \\
\hline 7 & Supply duct and return duct at the top from the same side & 294.772 & 294.542 & 28.2125 \\
\hline 8 & Supply duct and return duct at the bottom from the same side & 294.662 & 294.776 & 27.2103 \\
\hline 9 & Supply duct and return duct at the top from a different side & 297.387 & 297.218 & 23.9435 \\
\hline 10 & Supply duct and return duct at the bottom from a different side & 297.325 & 297.486 & 24.0131 \\
\hline 11 & Supply duct at the ceiling and return duct at the top & 294.178 & 293.893 & 27.5075 \\
\hline 12 & Supply duct at top and return duct at the ceiling & 296.089 & 295.892 & 30.4363 \\
\hline 13 & Supply duct at the ceiling and return duct at the bottom & 295.061 & 294.646 & 27.8 \\
\hline 14 & Supply duct at the bottom and return duct at the ceiling & 295.272 & 295.48 & 28.0311 \\
\hline
\end{tabular}




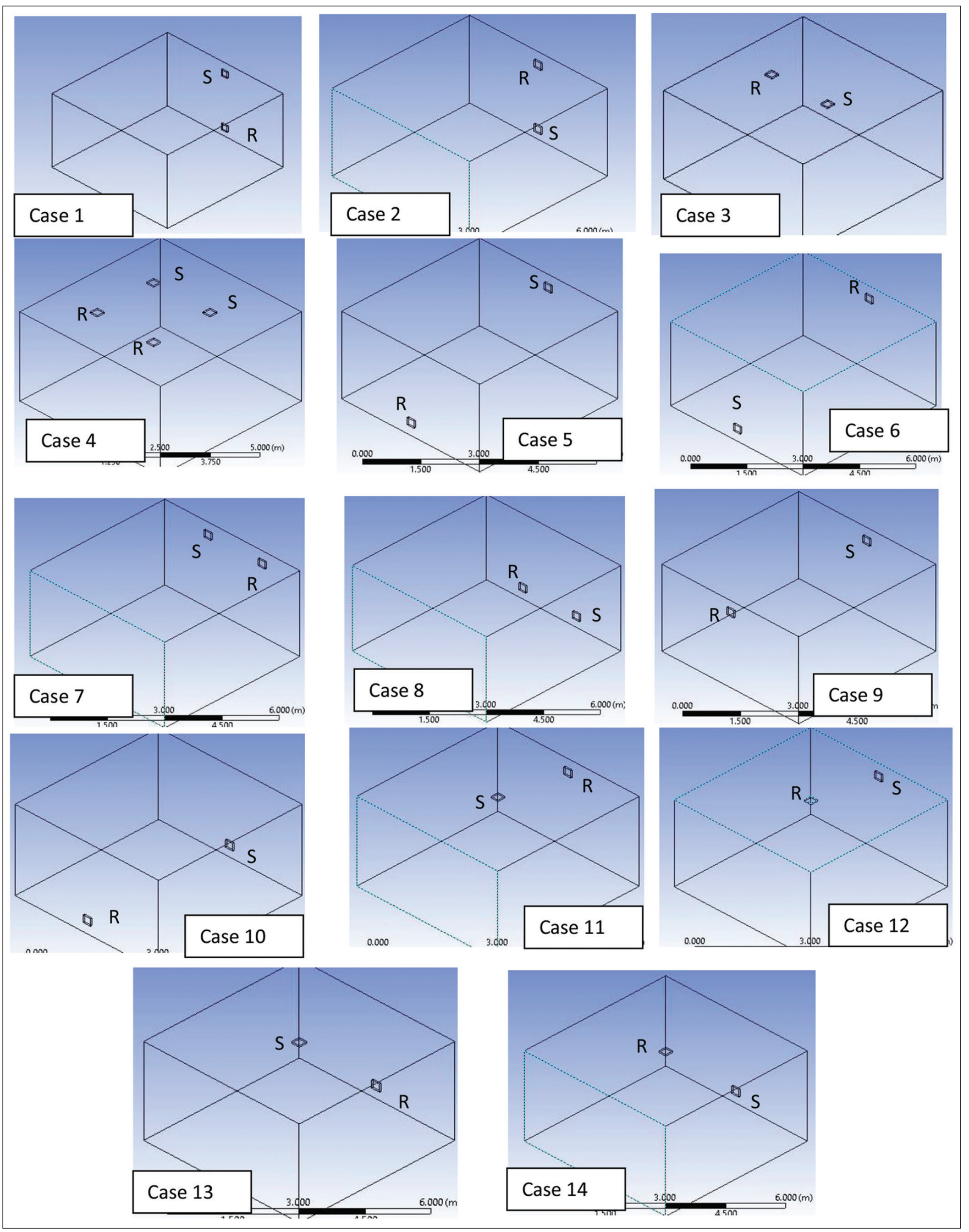

Figure 2: All different positions for supply and return ducts 


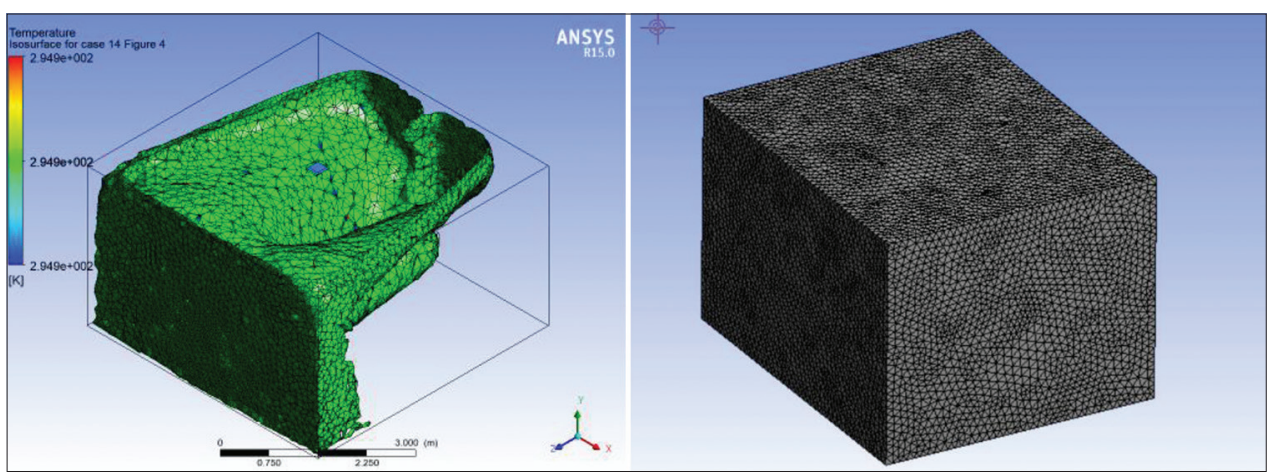

Figure 3: Fine mesh

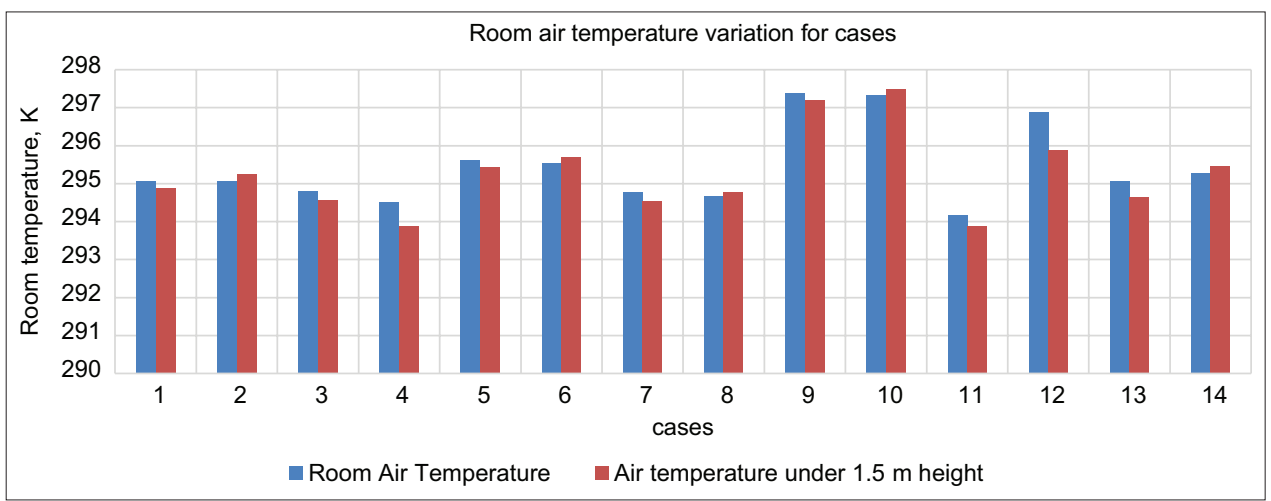

Figure 4: Average room temperature for all cases

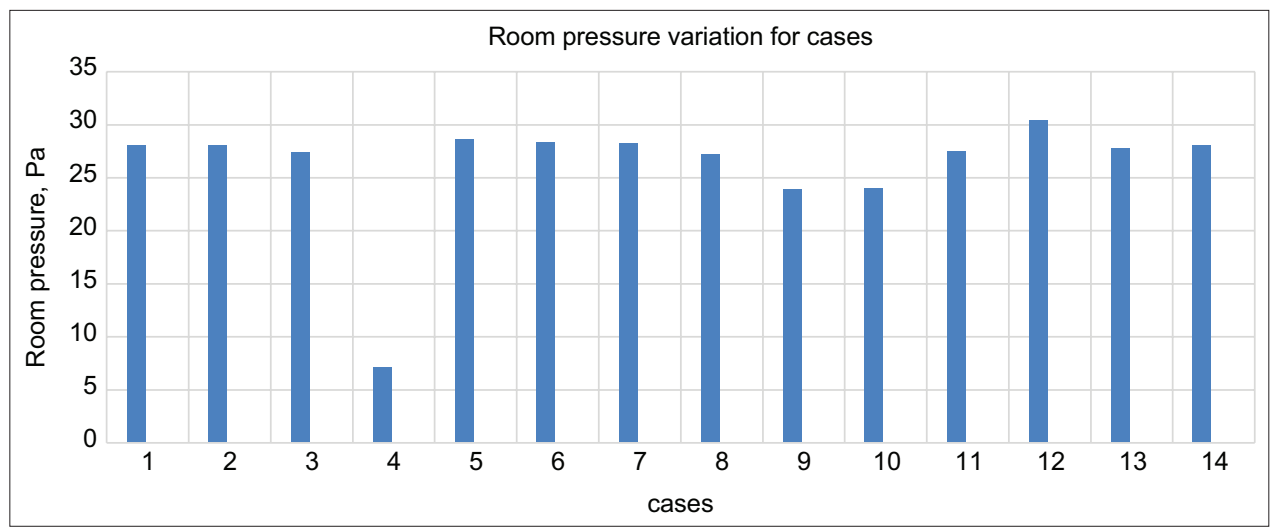

Figure 5: Average room pressure for all cases

system (IJV). (Kosonen and Mustakallio, 2010) Simulated a classroom with CFD and compared the indoor environment in the classroom in summer and winter conditions with mechanical air distribution systems that used several air distribution methods, including wall supply air grilles, ceiling diffusers, perforated duct diffusers, and a displacement ventilation unit. (Mustakallio and Kosonen, 2007) Thermal comfort in classrooms was investigated, as well as various air distribution systems such as a corridor-wall grille, a ceiling diffuser, a perforated duct diffuser, and displacement ventilation with varying load conditions. The current study will optimize the supply and return duct placements to provide effective air distribution while consuming the least amount of electricity in the room while maintaining thermal comfort.

\section{METHODOLOGY}

A room was designed and analyzed using (CFD - Fluent). The numerical test is performed on a room with dimensions $(5 \times 5 \times 3)$, the room is cooled through a supply diffuser of conditioned air and a grill for return air, (14) different cases are examined for supply and return duct positions while all other parameters remain constant. This study concentrated on the impact of supply and return ducts on temperature 


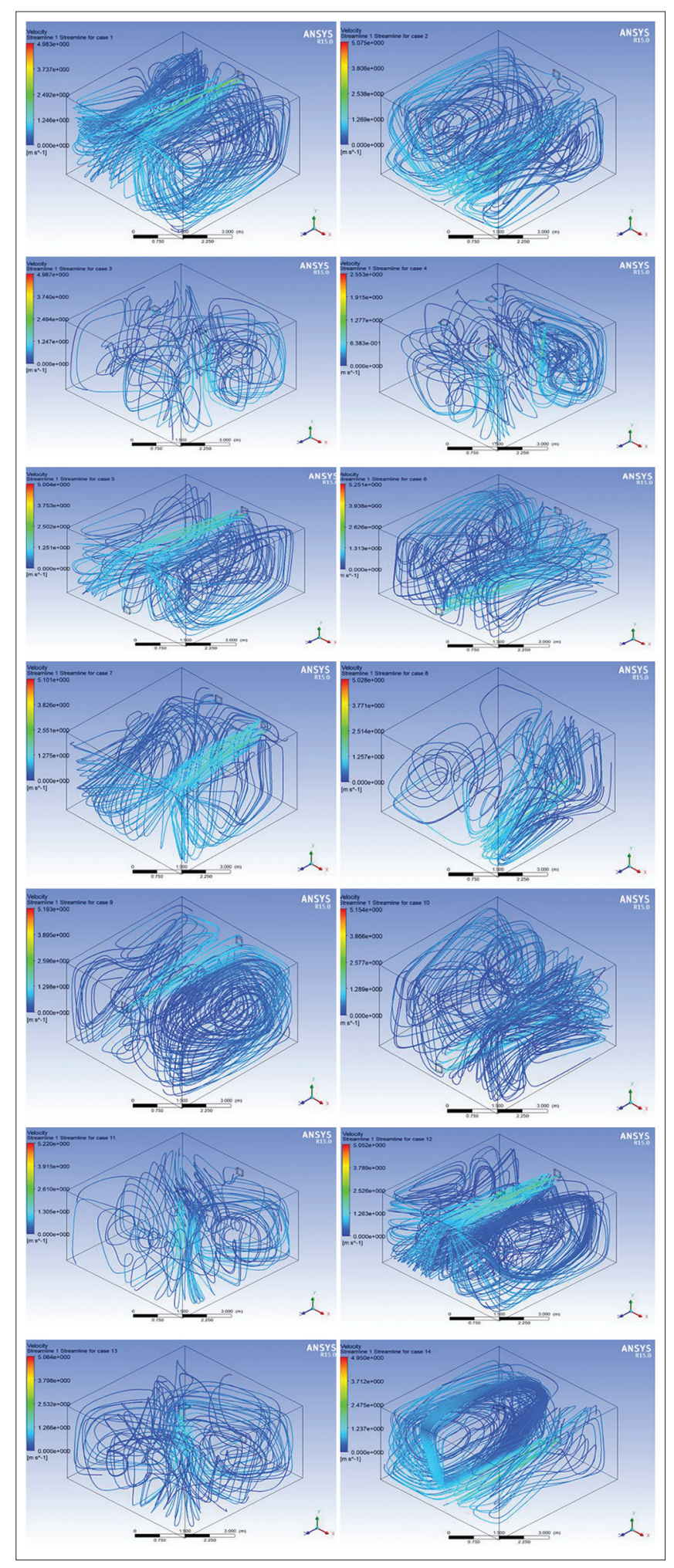

Figure 6: All-case velocity streamline

distribution and room temperature. CFD provides a link between natural theoretical fluid dynamics and experimental fluid dynamics. In the modern era, researchers are focusing on saving time and lowering the cost of experiments. Geometry is utilized to establish the geometry layout in every engineering simulation. There are numerous Computer-Aided Design programs available for creating geometry; however, commercial Ansys - Workbench Design Modeler Software has been designed specifically for geometry creation and simulation. [Figure 1] depicts the room geometry, including the placements of the supply and return air ducts, as well as their dimensions. [Figure 2] depicts 14 possible positions for the supply and return ducts.

Boundary Condition (remaining constant for all cases) Supply air velocity is $5 \mathrm{~m} / \mathrm{s}$ and Temperature is 290 .

Heat transfer from walls $=30 \mathrm{~W} / \mathrm{m}^{2}$

Return air pressure is $0 \mathrm{~Pa}$.

The roof and floor are insulated.

Steady-state time, pressure-based, gravity in the y-axis, absolute velocity, standard wall functions, turbulent flow k-epsilon model (2 eqn).

Fine mesh is used (36371 Nodes and 188815 Elements) as shown in [Figure 3].

Computer specification (Intel(R) Core (TM) i7-5600U CPU@2.60GHz 2.60 GHz, 12GB RAM).

The Mesh dependency test is used to find optimum meshing size, the test result showed that the mesh is just fine to have accurate results with setting residual difference for continuity and momentum results as 0.001 . The SIMPLE method is used for saves solution time while there is a low Grashof number (Gr.).

\section{RESULTS AND DISCUSSION}

The study of air distribution in a room is taken into account. The study explained the effect of supply and return duct positions on the minimum average temperature and pressure in a room, as well as the air temperature and pressure profile. All supply and return duct positions are considered, which results in 14 different cases, as shown in the [Tables 1 and 2, Figure 4] compare the minimum temperature for the entire room air volume and the lower half of the room air volume (under $1.5 \mathrm{~m}$ elevation) for all cases. Case (11) has a minimum room temperature according to the results. Case (4) is unique in that it fulfills the same results with double supply and returns ducts. The worst cases are (9) and (10) when the supply and return ducts are on the opposite wall side. [Figure 5] illustrates the pressure drop for every case; it is obvious that case (4) has the lowest pressure drop due to the double supply and return duct positions. [Figures 6] illustrate the streamline for air velocity in a room from each case. Minimum room temperatures are compared using histogram graphs, as shown in [Figure 7]. Case (4) shows that 75 percent of the 

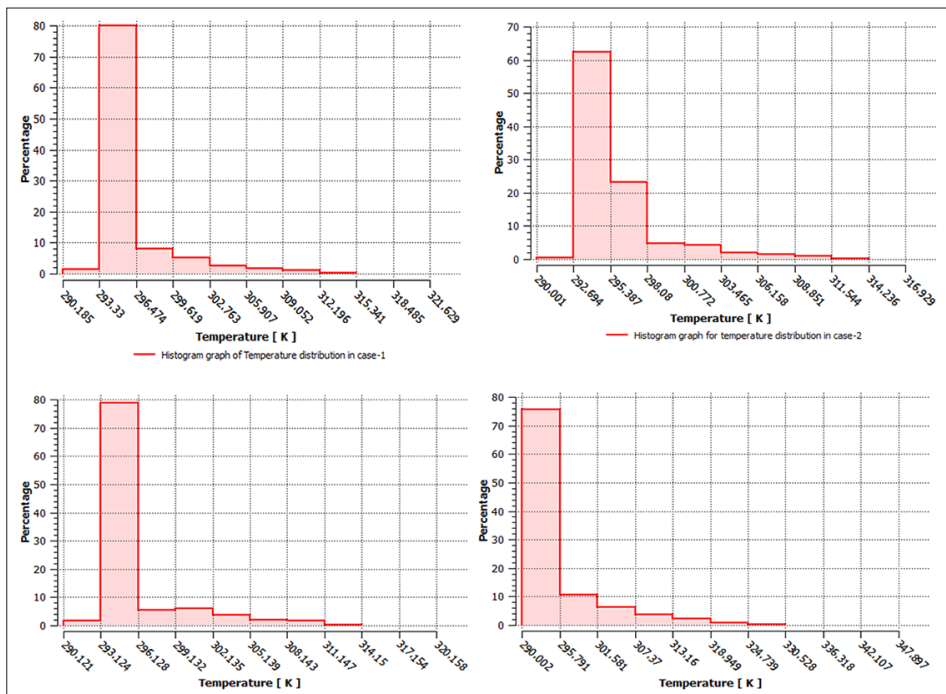

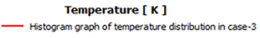

Temperature $[\mathrm{K}]$ ]
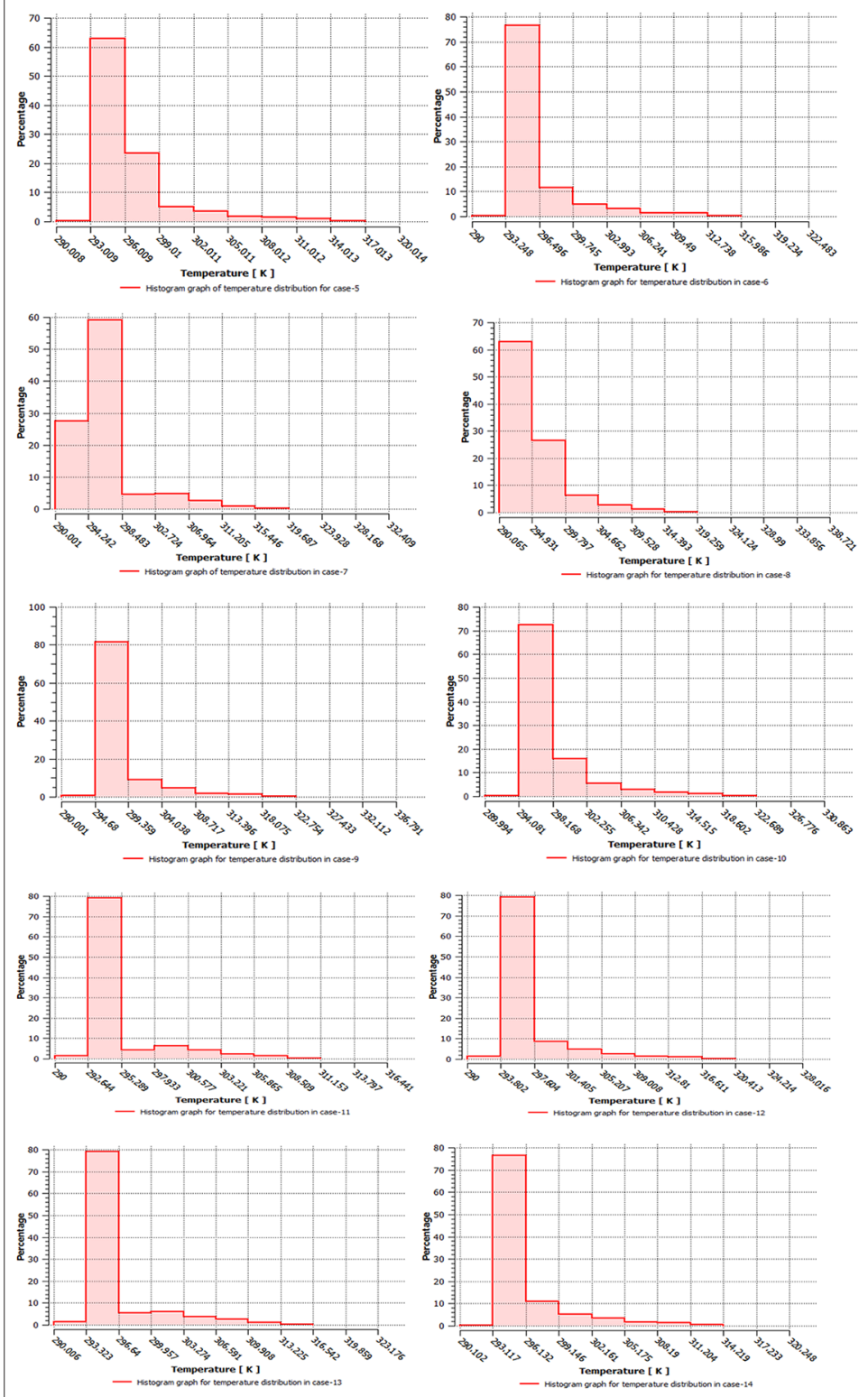

Figure 7: Temperature distribution histogram for all 

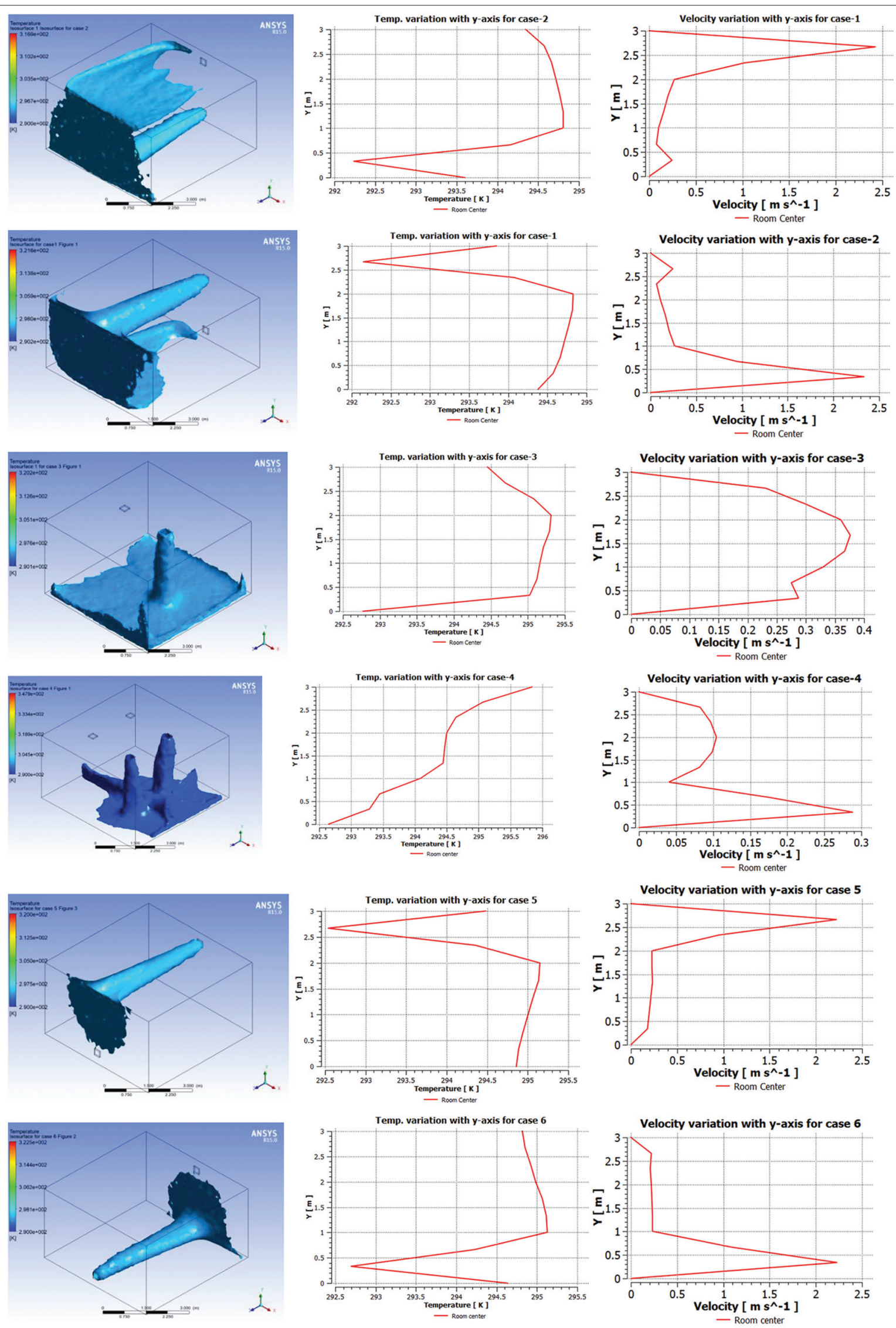

Figure 8: Isosurface temperature profile, temperature and velocity variation with the y-axis in the middle line of a room for all cases

(Contd...) 

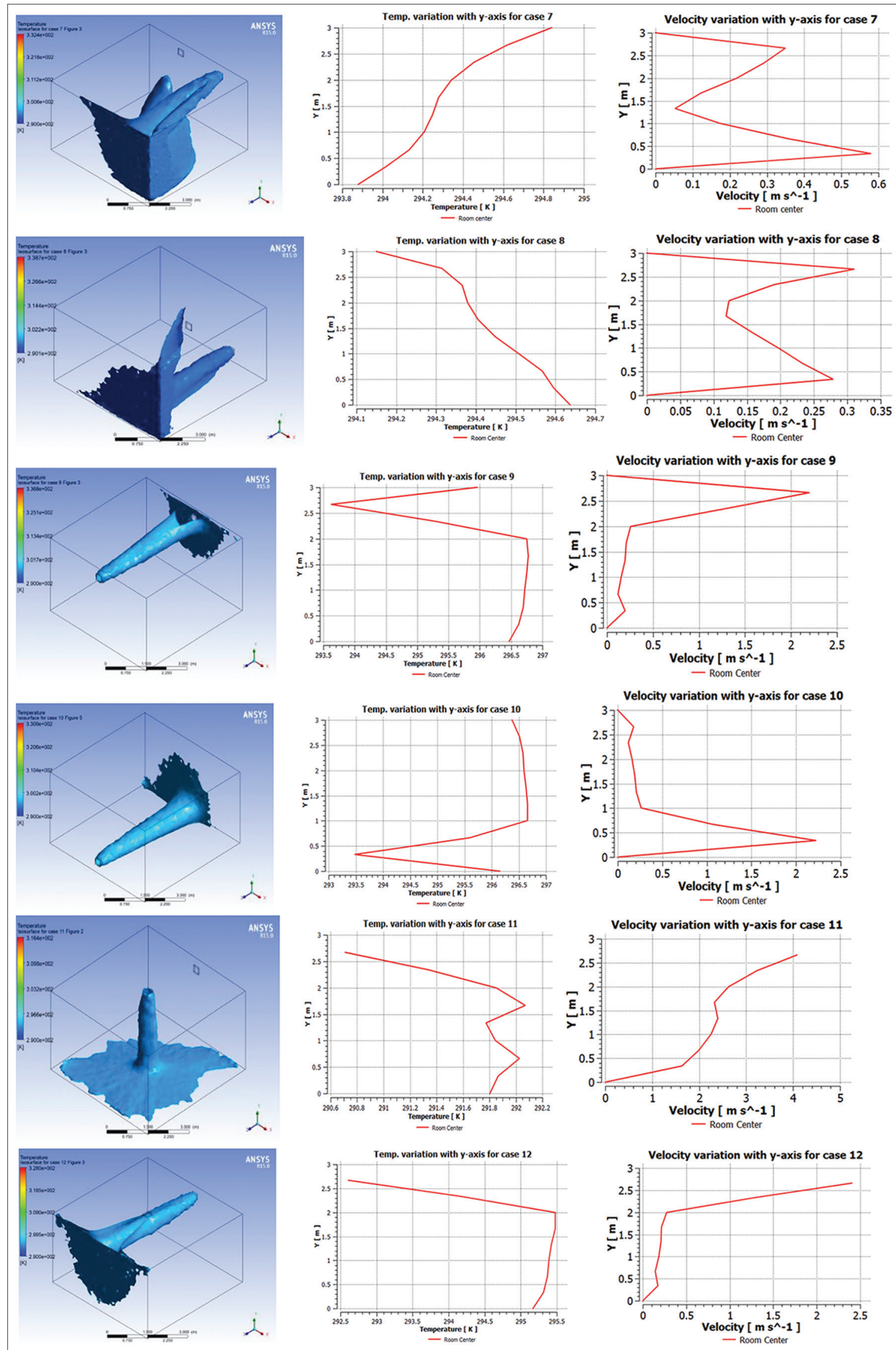

Figure 8: (Continued) 


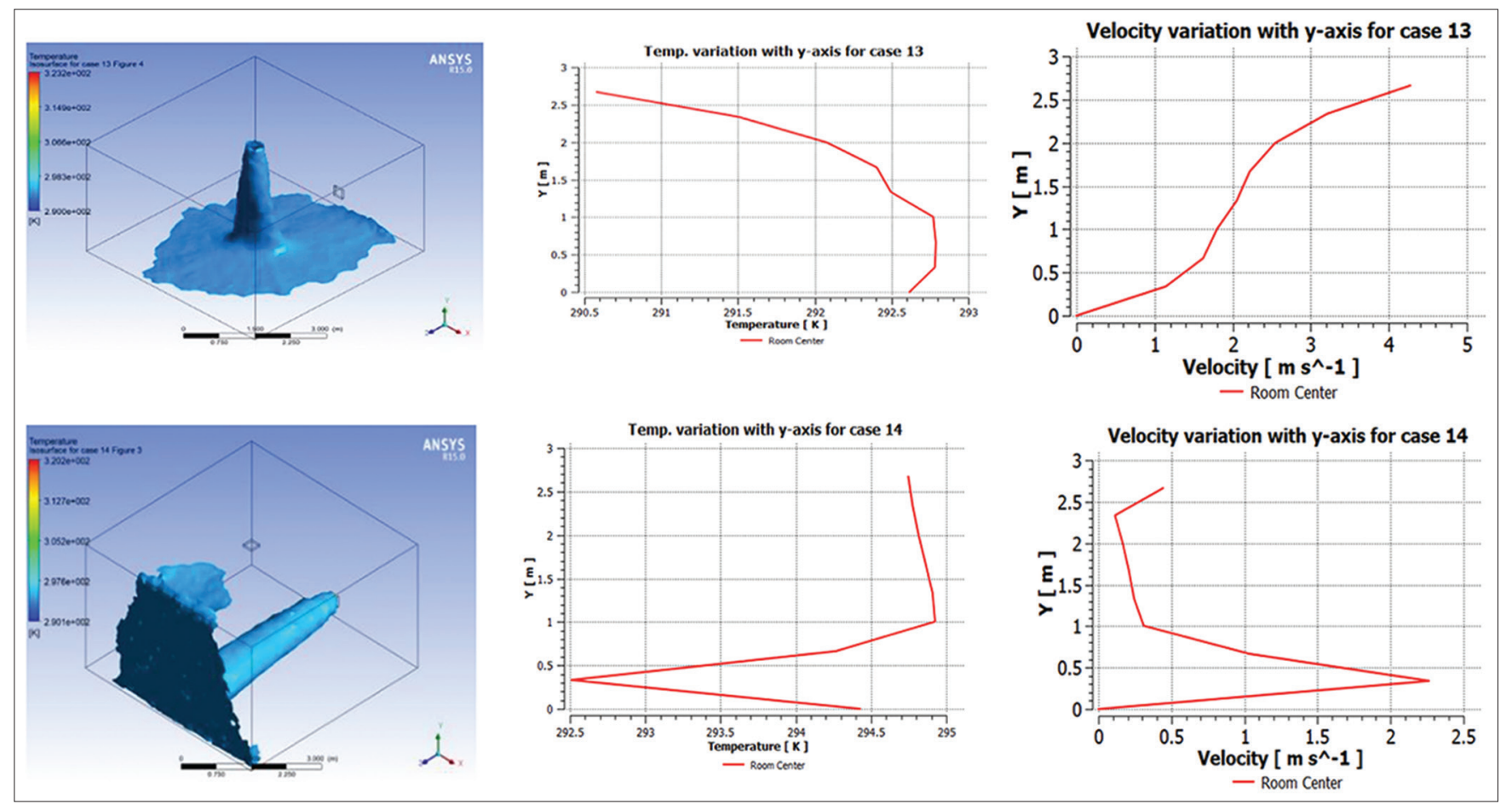

Figure 8: (Continued)

air volume has a temperature lower than $295 \mathrm{~K}$, while case (11) shows that $80 \%$ of the air volume has a temperature lower than $295 \mathrm{~K}$. The Isosurface temperature profile in a room is visualized in [Figure 8]. It also shows the change in temperature and velocity in a room center with varying room height. The findings are consistent with previous published work by (Khatri et al., 2017), demonstrating that the best condition occurs when both the supply and return diffusers are on the same side of the room. In this work, these scenarios were used in cases (1) and (2), while the worst scenarios are when supply and return are on the same side. This work yields the same results as (Qin and $\mathrm{Lu}, 2021)$, who demonstrate that installing a ceiling exhaust diffuser in the center increases air age and improves heat removal efficiency (Qin and Lu, 2021). The results were also compared with (Shokrollahi et al., 2020) by comparing temperature distribution throughout the middle room height; both studies produced a matching velocity profile.

\section{CONCLUSIONS}

CFD with ANSYS - Fluent was used in the current study to analyze room air distribution and optimize supply and return duct positions in a room to achieve minimum room temperature and pressure drop in a room with the best air distributions to ensure indoor thermal comfort. The histogram graph data shows the minimum room air temperature in relation to air volume. ANSYS V15.0 - FLUENT was used to do the model geometry, mesh, and analysis on a finite volume model of a 3-D room. It has been studied to utilize (14) different duct sites with the same room conditions. The data analysis leads to the following conclusions:

- The location of the supply and return ducts affects the room temperature. In all cases, the room has various minimum air temperatures for different duct locations. The lowest average air temperature in a room, according to the data, ranges between $(294 \mathrm{~K}$ and $297 \mathrm{~K}$ ) depending on the position of the ducts

- Increasing the number of supply and return ducts reduces pressure drop and lowers room air temperature, but it must have sufficient air distribution to provide thermal comfort

- The findings demonstrate that the case (11) can achieve a minimum room air temperature, with 80 percent of the room air volume having a temperature less than $(295 \mathrm{~K})$, with the supply duct in the middle of the ceiling and the return duct at the top of the wall. The worst cases are scenarios (9 and 10), in which supply and return ducts are opposite each other at the same level from the top or bottom of the wall and both supply the lowest room air temperature (297 K)

- Since the affected room volume (1.5 $\mathrm{m}$ height of the room) has a significant influence on human thermal comfort, the current study investigated the minimum room air temperature for the entire room volume and the lower half volume (effected room volume), with the results shown in [Table 2 and Figure 4]

- According to the study, (case 11), which has the opposite supply and return location, had the best room air 
distribution and the lowest room air temperature of all the other cases. When both the supply and return ducts were on the same side, the worst-case scenario occurred.

\section{RECOMMENDATIONS}

- The influence of temperature fluctuation on the outcomes, obviously defined, various air temperatures may need different duct positions

- Occupants and furniture in a room have a significant impact on room air distribution and thermal comfort, therefore the entire room may be examined for optimization.

\section{REFERENCES}

Abou-Deif, T. M. and E. E. Khalil. 2013. Numerical investigations of flow patterns and thermal comfort in air-conditioned lecture rooms using steady and unsteady techniques. Vol. 7(5). In: $11^{\text {th }}$ International Energy Conversion Engineering Conference. p917-922.

Ascione, F. 2021. The design of safe classrooms of educational buildings for facing contagions and transmission of diseases: A novel approach combining audits, calibrated energy models, building performance (BPS) and computational fluid dynamic (CFD) simulations. Energy Build. 230: A0199A.

Bamodu, O., L. Xia and L. Tang. 2017. A numerical simulation of air distribution in an office room ventilated by 4-way cassette airconditioner. Energy Procedia. 105: 2506-2511.

Ding, X. R., Y. Y. Guo and Y. Y. Chen. 2017. Design and simulation of an air conditioning project in a hospital based on computational fluid dynamics. Arch. Civil Eng. 63(2): 23-38.

Du, G., M. Lei, X. Chen, C. Huang, Y. Lv, H. Kang, R. Zhang and B. Zhang. 2016. The indoor thermal environment simulation and testing validation of a power plant turbine room in extreme cold area. Procedia Eng. 146: 632-639.

Hassan, N. M. S., M. M. K. Khan and M. G. Rasul. 2013. Temperature monitoring and CFD analysis of data centre. Procedia Eng. 56: 551-559.

Kareem, B. 2018. Experimental and theoretical study of dew point evaporative cooling system suitable for erbil climate. Polytech. J. 8(2): 102-118.

Khatri, R., A. P. Singha and V. R. Khare. 2017. Identification of ideal air temperature distribution using different location for air conditioner in a room integrated with EATHE-a CFD based approach. Energy Procedia. 109: 11-17.

Kosonen, R. and P. Mustakallio. 2010. Ventilation in classroom: A case-study of the performance of different air distribution methods. In: Proceedings of Roomvent 2010.

Lee, S., M. Nogami, S. Yamaguchi, T. Kurabuchi and N. Ohira. 2013. Evaluation of heat transfer coefficients in various air-conditioning modes by using thermal manikin, Chambéry, France, August 2628. In: $13^{\text {th }}$ Conference of International Building Performance Simulation Association.

Li, Y. and P. V. Nielsen. 2011. Commemorating 20 years of Indoor Air: CFD and ventilation research. Indoor Air. 21(6): 442-453.

Mustakallio, P. and R. Kosonen. 2007. Effect of Air Distribution Methods on Classroom Air Quality, Proceedings of Roomvent.

Ni, J., B. Jin, B. Zhang and X. Wang. 2017. Simulation of thermal distribution and airflow for efficient energy consumption in a small data centers. Sustainability. 9(4): 664 .

Pillai, S., S. Bhand, V. Shinde, S. Pawar and P. Katare. 2016. A review on CFD analysis in air-conditioning system. Int. J. Curr. Eng. Technol. 6(6): 1-3.

Qin, C. and. W. L. Lu. 2021. Effects of ceiling exhaust location on thermal comfort and age of air in room under impinging jet supply scheme. J. Build. Eng. 35: 101966.

Shokrollahi, S., M. Hadavi, G. Heidarinejad and H. Pasdarshahri. 2020. Multi-objective optimization of underfloor air distribution (UFAD) systems performance in a densely occupied environment: A combination of numerical simulation and Taguchi algorithm. J. Build. Eng. 32: 101495.

Song, J. and X. Meng. 2015. The improvement of ventilation design in school buildings using CFD simulation. Procedia Eng. 121: $1475-1481$.

Sudhangshu Sarma, O. 2016. Computational analysis of impact of the air-conditioner location on temperature and velocity distribution in an office room. Int. Res. J. Eng. Technol. 3(9): 1-7.

Thakur Dipendrasingh, P. and P. Parth. 2014. Quantification of air flow pattern in air conditioned room-a review. Int. J. Adv. Eng. Res. Dev. 1(12): 1-5.

Ye, X., Y. Kang, F. Yang and K. Zhong. 2019. Comparison study of contaminant distribution and indoor air quality in large-height spaces between impinging jet and mixing ventilation systems in heating mode. Build. Environ. 160: 106159.

Ye, X., Y. Kang, Z. Yan, B. Chen and K. Zhong. 2020. Optimization study of return vent height for an impinging jet ventilation system with exhaust/return-split configuration by TOPSIS method. Build. Environ. 177: 106858. 